\section{Perspectiva relacional nos estudos de movimentos sociais, protestos e organizaçóes}

ROSSI, Federico M. \& BÜLOW, Marisa von (orgs.). Social movement dynamics: new perspectives on theory and research from Latin America. Surrey, Ashgate, 2015. 231 páginas.

\section{Monika Dowbor}

As ondas recentes de mobilizaçóes nas ruas do Brasil postularam mais uma vez o rompimento com o Estado, seu sistema e formas de representação política. Junto com essa contestação vieram à tona a proclamação do caráter apartidário e horizontal dos movimentos, as inovaçóes no repertório de ação, os atores organizados em torno de pautas inéditas, a repressão do Estado, o uso de redes sociais, o papel das novas e velhas mídias, entre outros aspectos. Esses temas conformam uma nuvem de pautas urgentes que impulsionaram agendas de pesquisa, agregando pesquisadores antes alheios aos estudos dos movimentos sociais. O ar de novidade gerou certa neblina e ofuscou linhas de pesquisa em franca expansão no Brasil e também em outros países da América Latina, como mostra a coletânea aqui resenhada Social movement dynamics: new perspectives on theory and research from Latin America. Refiro-me às complexas e diversas relaçóes dos movimentos sociais com as instituiçóes e outros atores sociais e estatais. $\mathrm{Na}$ esteira de outros trabalhos já publicados no Brasil, portanto, este livro se propóe a dar continuidade a esse tipo de estudo. Sua principal contribuição, conforme anunciam os organizadores da coletânea, Federico M. Rossi e Marisa von Bülow, consiste em resgatar e elaborar os instrumentos analíticos capazes de analisar os movimentos sociais em tipos concretos de entornos socioeconômicos e políticos e em interaçóes com o Estado, suas instituiçóes e outros atores. Em síntese e também de acordo com a formulação dos organizadores, as análises têm um enfoque relacional, termo de inspiração neoinstitucionalista (Skocpol, 1985).

Para quem não tem acompanhado o debate acadêmico sobre os movimentos sociais no Brasil, um parágrafo de atualização. Desde os anos 2000, um conjunto de estudos nessa área vem demostrando a insuficiência do foco apenas na política de confronto ou nas diversas formas de protesto. Além de ampliar conceitos como o de repertório de ação (Abers, Serafim, Tatagiba, 2014), cunhar novos, como o domínio de agência (Lavalle, Houtzager e Castello, 2011) ou padrōes de ação coletiva (Carlos, 2012), entre outros, uma consequência direta dessa inflexão consistiu no desafio de incluir nas análises tanto as instituiçóes, quanto outros atores. $\mathrm{O}$ que caiu por terra, afinal, foi a separação analítica de dinâmicas próprias dos movimentos, de um lado, das do Estado, de outro. Termos como autonomia e cooptação, que permitiam separar o mundo dos movimentos daquele do Estado, abrindo espaço para análises dicotômicas, deixaram de orientar as pesquisas, e a perspectiva das interaçóes colocou-se para os estudiosos exigindo a inclusão analítica do Estado. O caráter relacional e mutuamente transformador, ao qual Ruth Cardoso (1984) já se referia nos anos de 1980 como forma de analisar as relações entre movimentos e instituições, se impôs.

O livro leva justamente essa tarefa coletiva adiante. Voltado claramente aos pesquisadores desse campo, ele reconhece os avanços e as especializaçóes já existentes, e sua organização interna reflete isso. Os capítulos são agrupados em três blocos: no primeiro, discute-se como lidar com as interaçóes entre os movimentos e o Estado sem cair em dicotomias clássicas, como autonomia versus cooptação ou mobilização versus institucionalização; no segundo, a reflexão focaliza as possibilidades de lidar analiticamente com os protestos e, no último, discutem-se os avanços no campo dos formatos organizacionais de movimentos sociais. Os autores, todos pesquisadores de longa carreira, fazem, em cada capítulo, uma sólida e abrangente revisão da literatura de seu campo, o que em si já é uma fonte importante de referência para aqueles que querem se inteirar desses debates.

A base empírica da coletânea é a América Latina, mas seus colaboradores não se propuseram a fazer um diagnóstico dos movimentos neste continente, nem construir uma nova teoria, algo à la teoria decolonizada. Sua proposta consiste em trazer e evidenciar aspectos analíticos capazes de capturar os movimentos sociais em interação com outros 
atores e instituiçóes a partir de instâncias empíricas localizadas na América Latina. É inevitável que as contradiçóes, as desigualdades e os marcos históricos da América Latina se imponham, mas o desenvolvimento teórico-analítico avança no diálogo e com o conhecimento produzido pelos pesquisadores de países desenvolvidos. Tendo em vista a variedade de temas abordados, esta resenha levará o(a) leitor(a) pelos capítulos, ressaltando na medida do possível as formas analíticas que traduzem esse enfoque relacional.

Se é do consenso desse campo de pesquisa que as ações dos movimentos sociais não se restringem a confrontos públicos (Abers, Tatagiba e Serafim, 2014; Carlos, 2012; Guigni e Passy, 1998; Jasper, 2004), de que maneira analítica poderíamos capturar esse tipo de ação quando ele não tem visibilidade pública? Um caminho já oferecido pela literatura abrange a lista de táticas via instituições, tais como ocupação de cargos em governos, participação em instituiçóes participativas, entre outras. A proposta de Federico M. Rossi, no capítulo "Conceptualizing strategy making in a historical and collective perspective", sugere distinguir e tipificar o nível intermediário de ação que se situa entre o repertório geral de açóes e as táticas pontuais: o repertório de estratégias. Se não for de caráter confrontacional, o movimento social poderia assumir outras estratégias desse repertório. Baseando sua proposta no estudo dos movimentos sociais na Argentina, Rossi ressalta os seguintes estilos de atuação: frente popular multiclasse, aliança insurgente com a direita; colonização do Estado, estratégia de testemunho; estratégia sindicalista e estratégia de foco moderado e "onguização". Cada uma dessas estratégias daria um contorno para um número bem maior de táticas.

A escolha de uma estratégia é pautada pela trajetória pregressa do movimento, e para acessá-la Rossi cunha o conceito de "estoque de legados". Com ele o autor dialoga diretamente com as raízes históricas do repertório de ação dos movimentos sociais, mas o circunscreve localmente na medida em que se refere ao conjunto de experiências de lutas passadas concretas que são sedimentadas, compartilhadas e aprendidas entre os atores. Mostra assim as raízes históricas das estratégias, mas não associadas a macroprocessos da formação dos
Estados-nação, e sim aos processos de um Estado concreto, no caso, a Argentina.

Permanecendo no nível das microações, o capítulo de Rebecca Abers e Luciana Tatagiba, "Institutional activism: mobilizing for women's health from inside the Brazilian bureaucracy" ajuda a entender uma das táticas, a saber, a de ocupação de cargos em governos. As autoras propóem-se a descrever o que os ativistas, de fato, fazem quando assumem esses cargos, tomando por base o caso de políticas públicas de saúde da mulher no governo Dilma (2010-2013). No entanto, mais que efeitos, elas focam analiticamente os constrangimentos aos quais os ativistas estão expostos e os recursos de que dispóem. Essa análise exige que se olhe o ativista institucional, categoria cunhada para denominar o militante no Estado, do ponto de vista do movimento e do Estado. A relação com o primeiro é ambivalente. Pode ser de fogo amigo, na medida em que os militantes de fora pressionam e criticam as açóes de ativistas dentro do Estado. Mas o ativista pode usar politicamente suas redes para buscar apoio político, bem como para construir alianças ou para executar tarefas relacionadas com a implementação de políticas públicas. A relação com o Estado também deveria ser, em tese, ambivalente. Isto é, composta por possibilidades e constrangimentos. Mas, de certa forma, as autoras deixam no segundo plano a discussão sobre a permeabilidade do Estado (Marques, 2006), que permitiu o acesso do movimento a algumas de suas instituiçóes e tomam as dificuldades dos militantes como a descrição analítica do Estado. O Estado aparece hostil e pesado, apenas constrangendo a ação de ativistas. É hostil na medida em que está sujeito às dinâmicas de coalizóes partidárias, que tornam os gestores públicos menos favoráveis às pautas do movimento. É pesado enquanto máquina administrativa e burocrática ao exigir processos e procedimentos que tornam a implementação das ações mais lenta. A análise do Estado pelo prisma dos ativistas em si é interessante, mas dificulta a compreensão mais abrangente do funcionamento das instituiçóes. Para podermos avançar nessa tarefa, um caminho interessante poderia ser agregar as abordagens e categorias já existentes sobre o Estado aos estudos dos movimentos sociais em interação com as instituições. 
No caso dos estudos sobre movimentos movidos frequentemente pelas novidades que esses atores trazem para a cena política, corremos certo risco de adotar as categorias práticas como lentes de análise. Este já foi o caso da "autonomia" como postulado dos movimentos nos anos de 1970, que foi adotada para descrever a relação entre os movimentos sociais e o Estado pela literatura acadêmica (Lavalle e Szwako, 2015). Como consequência, excluíram-se das pesquisas as interaçóes realizadas via instituiçóes (Cardoso, 1984). Termos como antipartidarismo, horizontalidade ou autonomia expressam tensóes e ambivalências que precisam ser entendidas como percepçóes e açóes de atores, para depois serem reconstruídas empiricamente. Ann Mische, no capítulo "Patrisan performance: the relational construction of Brazilian youth activist publics", dá conta desse desafio de maneira brilhante. Ela mostra, com base na pesquisa sobre o impeachment do presidente Collor, em 1992, como a relação entre o ativismo cívico e o partidário já era tensa e problemática, e o antipartidarismo surgia como um postulado. $\mathrm{O}$ movimento estudantil tornou-se antipartidário então? A análise cuidadosa da autora mostra que os jovens ativistas já eram portadores de vínculos com diferentes organizaçóes, entre as quais os partidos, e como faziam um jogo de ativação e desativação de vínculos e pertencimentos. Isto é, os ativistas escolhem deliberadamente do seu leque de pertencimentos aqueles vínculos que possibilitam o diálogo e a ação no espaço em que se encontram.

No capítulo de Paul D. Almeida, "The role of threats in popular mobilization in Central America", muda-se o foco analítico para discutir mais especificamente protestos, mas persistirá aqui a pergunta sobre como envolver o Estado na reflexão empreendida. Desastres socioambientais, governos reacionários, crises econômicas... O que os movimentos sociais fazem contra o retrocesso do mundo? Essa pergunta nos leva ao cerne desse texto, que chama a atenção para os fatores explicativos da mobilização de ação coletiva. $\mathrm{O}$ autor destaca do clássico conceito de oportunidade política (McAdam, 2006) sua faceta menos explorada, a saber, a ameaça política. A investigação das mobilizações da América Central reforça o papel das ameaças ou das condiçóes negativas como desencadeadoras da ação coletiva. Almeida aproveita a classificação já existente, tratando, pois, da ameaça de repressão do Estado, do indício dos problemas econômicos atribuídos ao Estado e dos prejuízos ambientais. $\mathrm{O}$ Sul geopolítico está repleto desses fenômenos que podem provocar a ação dos movimentos ainda que nem sempre.

À semelhança do argumento utilizado nos anos de 1960 de que a penúria e a pobreza não constituem condição suficiente para o desencadeamento de uma ação coletiva, Almeida propóe um arcabouço explicativo mais amplo para entender as condiçôes em que cada tipo de ameaça incita tal ação. Vejamos o exemplo dos problemas econômicos. Aqui se enquadram as recorrentes campanhas contra a política neoliberal, que, no século XXI, têm contemplado ampla participação popular na América Central. Para que a mobilizaçáo seja alavancada, segundo o autor, é preciso que haja a percepção de que o Estado tem responsabilidade nos problemas econômicos. A mobilização acontece então, em decorrência de suas políticas públicas combinadas com a existência de mecanismos democráticos, como as eleiçóes.

Almeida assume que a identificação das ameaças é apenas parte da explicação. Em torno de cada uma das ameaças, afirma o autor ao terminar o artigo, há processos prévios de decisão e de interação, os quais precisam ser incorporados na análise. Ao indicar essas novas frentes, ele amplia o escopo para além dos protestos, trazendo o Estado e outros atores para dentro da análise. Ultrapassar um enfoque que se restringe apenas ao movimento social é um dilema que os estudiosos da área enfrentam, uma vez que a agregação de novos elementos analíticos pode ser onerosa e nem sempre viável. Tanto na proposta de Almeida, como na de Abers e Tatagiba, uma solução seria conduzir as pesquisas com equipes mistas, compostas por especialistas em instituiçóes políticas, grupos de interesse e movimentos sociais.

A agenda de pesquisa sobre os efeitos dos movimentos sociais tem sido retomada e dispóe de proposiçóes robustas e arcabouços explicativos (Amenta et al., 2010; Bosi, Giugni e Uba, 2016). Os efeitos são usualmente classificados como de intramovimento (referentes a ativistas, a aspectos organizacionais e à influência em outros movimen- 
tos) e extramovimento (culturais e políticos) (Earl, 2000). Também podem ser organizados como efeitos previstos e não previstos. São estes últimos, ainda pouco estudados, que Ligia Tavera Fenellosa aborda em seu capítulo "Evenful temporality and the unintended outocmes of Mexico's Earthquake victims movement". Trata-se de uma empreitada arriscada, na medida em que o imprevisto significa aquilo que não faz parte das reivindicaçóes dos movimentos sociais, ou seja, aparentemente quase tudo. A força de sua proposição reside no caráter culturalista (Jasper, 2005) e que ainda assim consegue incluir em sua análise o sistema político.

O caso estudado refere-se ao mobilização decorrente do grande terremoto que devastou a cidade do México (DF) em 1985. A demanda da população atingida girava em torno da moradia, e a mobilização nesse sentido foi bem-sucedida. Contudo, não fazia parte das reivindicaçóes a democratização das relaçóes com o Estado, ainda que, na época do terremoto, milhóes de habitantes da capital não eram representados por nenhuma instância legislativa, e as autoridades locais não eram eleitas pelo voto popular. Não obstante, a importância simbólica da ação solidária de cidadãos percebidos até então como indiferentes e individualistas foi aproveitada pelos atores políticos. A participação cidadã entrou, assim, na agenda de governo e foi potencializada pelos partidos da oposição. $\mathrm{O}$ efeito imprevisto, portanto, consistiu na convocação de um órgão de participação cidadã que, apesar de ter sido aquém do almejado pela oposição, significou, na visão da autora, a maior mudança qualitativa na democratização do Distrito Federal do México. Do ponto de vista analítico, para poder capturar esse tipo de efeito é preciso adotar, defende a autora, uma visão do movimento social como sequência de eventos históricos dentro de uma cadeia mais ampla de ocorrências. Eles se tornam históricos à medida que sua pauta, visão, transgressão e ruptura são capturados e expandidos por outros atores presentes na cena política. Esse caminho analítico parece bastante atraente e possui a beleza de evidenciar o caráter normativo dos movimentos sociais e seu poder de difusão.

Os dois últimos capítulos dedicam-se às formas organizacionais dos movimentos sociais. En- tendê-las como elementos responsáveis pelas mobilizaçôes derrubou a visão dominante até a década de 1970 sobre a espontaneidade dos ciclos de protesto. No entanto, a vertente responsável por esse novo argumento, conhecida como "mobilização de recursos", ficou na sombra da teoria do processo político e não desenvolveu amplas linhas de pesquisa próprias (McCarthy, 1999). Com o capítulo de Adrian Gurza Lavalle e Marisa von Bülow - "Institutionalized brokers and collective actors: diferente types, similar challanges" - adentramos novamente nesse complexo e diverso universo das organizações, detendo-se mais especificamente na presença de entidades intermediadoras (brokers), criadas por atores singulares e institucionalizadas. Os autores contribuem com uma análise detalhada dos tipos e dos papéis que elas podem desempenhar. Diferenciam três tipos, a depender do vínculo mais ou menos formal com seus membros - associaçóes de pico, conglomerados associativos e entidades multisetoriais -, que podem desempenhar o papel de tradutor, coordenador, articulador e representante. O capítulo contribui para delinear quais são os prós e os contras ligados à institucionalização de organizaçôes dos movimentos bem como ilumina as maneiras pelas quais as formas organizacionais são criadas e recriadas e o que gera sua continuidade.

Entre os capítulos que mais claramente dirigem o olhar para as diferenças entre o Sul e o Norte do planeta está o de Rose J. Spalding: "Domestic loops and deleveraging hooks: transnational social movements and the politics of scale shift". A autora trata do transnacionalismo dos movimentos sociais, isto é, o ativismo transnacional, tema que já inspirou, de acordo com ela, vários estudos e gerou categorias e proposiçóes, como o trabalho de Keck e Sikkink (1998) e o estudo de Sidney Tarrow (2005). Spalding ressalta o contexto político da recente democratização, a guinada para a esquerda e os conflitos decorrentes da pressão externa para a implementação das regulamentaçóes neoliberais. A própria instância empírica da autora - a exploração de recursos minerais - também situa a discussão na problemática muito presente no Sul global. A autora contribui para o debate introduzindo novos ângulos analíticos ancorados nessa regiâo do planeta, mas que também podem ser utilizados no Norte. $\mathrm{O}$ 
transnacionalismo lateral, termo proposto por ela, é um deles. Trata-se de relações qualitativamente diferentes no ativismo transnacional, uma vez que mais igualitárias entre os parceiros regionais em comparação com as existentes nas conexões entre Norte e Sul, marcadas negativamente por diferenças em termos culturais e de poder. Os atores inseridos nas relaçóes circunscritas pelo transnacionalismo lateral compartilham de situaçóes parecidas, o que permite uma maior difusão de práticas e estratégias, estabelecendo uma troca mais rente à realidade.

A coletânea termina com uma conclusão de Margaret Keck. A cobrança que porventura poderia ser feita por falta de uma definição acerca de movimento social se dissolve neste texto. Deixando explícita a perspectiva relacional que marca o livro, ela afirma: "precisamos nos perguntar não só de onde eles [movimentos sociais] vêm e para onde acham que vão, mas também qual é a natureza das arenas em que eles desenvolvem suas lutas e quais são as capacidades das instituiçôes sobre as quais recaem as demandas - normalmente setores do Estado - para responder às reivindicaçōes” (p. 217). Nesse sentido, o prisma analítico dos movimentos sociais como desafiadores do status quo se mantém com todo o vigor para entendermos como se constrói e se reconstrói a autoridade política diante das necessidades dos cidadãos.

\section{Bibliografia}

ABERS, Rebecca; SERAFIM, Liza \& TATAGIBA, Luciana. (2014), "Repertórios de interação Estado-sociedade em um Estado heterogêneo: a experiência na era Lula”. Dados - Revista de Ciências Sociais, 57, 2: 325-357.

AMENTA, Edwin; CAREN, Neal, CHIARELLO, Elizabeth \& SU, Yang. (2010), "The political consequences of social movements". Annual Review of Sociology, 36: 287-307.

BOSI, Lorenzo; GIUGNI, Marco \& UBA, Katrin. (2016), The consequences of social movements. Cambridge, Cambridge University Press.

CARDOSO, Ruth Correa Leite. (1984), "Movimentos sociais urbanos: balanço crítico", in
Bernardo Sorj e Maria Hermínia Tavares de Almeida (orgs.), Sociedade e politica no Brasil pós-64, São Paulo, Brasiliense.

CARLOS, Euzeneia. (2012), Movimentos sociais e instituiçóes participativas: efeitos organizacionais, relacionais e discursivos. São Paulo, tese de doutorado, Faculdade de Filosofia, Letras e Ciências Humanas da Universidade de São Paulo.

EARL, J. (2000), "Methods, movements and outcomes: methodological difficulties in the study of extramovement outcomes". Research in Social Movements, Conflicts and Change, 22: 3-25.

GUIGNI, Marco \& PASSY, Florence. (1998), "Contentious politics in complex societies: new social movements between conflict and cooperation", in Marcos Giugni, Doug McADam e Charles Tilly (orgs.), From contention to democracy, Lanham, Rowman \& Littlefield Publishers.

KECK, Margaret E. \& SIKKINK, Kathryn. (1998), Activists beyond borders. Ithaca, Cornell University Press.

LAVALLE, Adrián Gurza; HOUTZAGER, Peter \& CASTELLO, Gabriela. (2011), "La construcción política de las sociedades civiles", in Adrián Gurza Lavalle (org.), El horizonte de la politica: Brasil y la agenda contemporánea de investigación en el debate internacional, México, Ciesas,p p. 207-267.

\& SZWAKO, José. (2015), "Sociedade civil, Estado e autonomia: argumentos, contra-argumentos e avanços no debate". Opiniáo Pública, 21 (1): 157-187.

JASPER, James. (2004), “A strategic approach to collective action: looking for agency in social movement choices?". Mobilization, 9 (1): 1-16. (2005), "Culture, knowledge, and politics”, in T. Janoski, R. R. Alford A. M. Hicks e M. A. Schwartz (orgs.), The handbook of political sociology: States, civil societies, and globalization, Cambridge, Cambridge University Press, pp. $115-134$

MARQUES, Eduardo. (2006), "Redes sociais e poder no Estado brasileiro: aprendizados a partir de políticas urbanas". Revista Brasileira de Ciências Sociais, 21 (60): 15-41. 
MCADAM, Doug. (2006), "Conceptual origins, current problems, future directions", in Doug McAdam, John D. McCarthy e Mayer Zald (orgs.), Comparative perspectives on social movements: political opportunities, mobilizing structure, and cultural framings, Cambridge, Cambridge University Press.

MCCARTHY, John D. (1999), "Reinvigorating ZMRM: Zald/McCarthy resource mobilization". Paper presented at Zaldfest, a conference held to recognize the contributions of Mayer Zald to the sociology of organizations, social movements, and culture, on 17-18 September 1999. Disponível em http://deepblue.lib.umich.edu/bitstream/handle/2027.42/51351/587. pdf?sequence $=1$, consultado em 30/6/2016.

SKOCPOL, Theda. (1985), "Bringing the state back in: strategies of analysis in current research", in Peter B. Evans, Dietrich Rueschemeyer e Theda Skocpol, Bringing the State back in, Cambridge, Cambridge University Press.

TARROW, Sidney. (2005), The New Transnational Activism, Cambridge, Cambridge University Press.

\section{Monika Dowbor é professora do Programa de Pós-graduaçấo em ciências sociais da Universidade do Vale do Rio dos Sinos (Unisinos), Sáo Leopoldo (RS), e pesquisadora do Centro Brasileiro de Análise e Planejamento (Cebrap). E-mail: mdowbor@gmail.com.}

DOI: $10.17666 / 329517 / 2017$ 